\title{
A Three-Level Software Support Platform for the GRADUATE ATTRIBUTE-CURRICULUM IMPROVEMENT PROCESS
}

\author{
David Taylor \\ University of Ottawa \\ dtaylor@uottawa.ca
}

\begin{abstract}
Since 2014, the Canadian Engineering Accreditation Board (CEAB) has required that accredited engineering programs implement a process of Graduate Attribute Assessment and Continual Improvement (GA/CI). At the University of Ottawa, the GA/CI process has been designed around three levels of administration (Faculty, Program and Course) that also utilizes Vena Solution's cloud database system structured around Excel. This paper describes the Faculty's three-tiered administrative structure and discusses the implementation of the Vena system at each of these levels.

Keywords: Graduate Attributes, Indicators, Continual Improvement Process, accreditation, CEAB, student performance, undergraduate student tracking
\end{abstract}

\section{INTRODUCTION}

Since 2014, the Canadian Engineering Accreditation Board (CEAB) has required that accredited engineering programs implement a process of Graduate Attribute Assessment and Continual Improvement $(\mathrm{GA} / \mathrm{CI})$. The $\mathrm{GA} / \mathrm{CI}$ is based on twelve attributes established by the Board; however, the details of the implementation have been left to the discretion of the individual Higher Education Institutions (HEIs). Despite this open-ended nature of the implementation process, there is now a growing consensus between the CEAB and the HEIs as to the elements required to effectively implement a $\mathrm{GA} / \mathrm{CI}$ framework within their programs; these include curriculum maps, well-defined indicators for the various graduate attributes, identification of appropriate assessment tools, a systematic feedback process for assessing the existing programs based on measurements across years of study, and engagement by external stakeholders [1].

Some institutions have followed a five-step process outlined by EGAD to align their programs to the CEAB requirements, while others have adopted an independent approach [2]. None-the-less, engineering programs at various stages have still struggled to design and adopt an overall process that they hope will meet both the stated and unstated expectations of Engineers Canada and the CEAB.
At the University of Ottawa, the initial implementation of the GA/CI process was left to the discretion of each department responsible for given program. However, early adopters within the Faculty set the trend for the others, so that once all departments had implemented a GA/CI process, the essentials remained the same across the various undergraduate programs. Despite this, the data collection process remained peculiar to each department and while these were consistently based on Excel spreadsheets [3], the details of process varied from Department to Department and the data collection remained laborious. Further, data analysis was limited to the departmental level in each case.

In 2017 the Faculty took steps to standardize the data collection and analysis by adopting a three-tier structure [4] that coordinated responsibilities between the Faculty, program and course levels and that exploited Vena Solutions' cloud-based service with its Excel front end for data logging and analysis [5]. The process is currently in pilot testing.

This paper discusses the overarching administrative structure to manage the Graduate Attribute data collection process, together with details concerning the specific implementation using Vena Solution's software infrastructure.

\section{ADMINISTRATIVE STRUCTURE, ROLES AND PROCESS FLOW}

The University of Ottawa's Graduate Attribute tracking system centers on four principal components: the CEAB's 12 Graduate Attributes (GAs), Program-level Indicators (Is) associated with each Graduate Attribute, course-level Learning Outcomes (LOs), and course Assessment Tools (ATs), where the GA, I and LO components offer increasing degrees of granularity and specificity regarding student competencies and where the ATs provide a means to evaluate these competencies on a student-by-student basis. It also identifies three levels of responsibility: those of the Faculty, the Program and the instructor (Course). 
Figure 1 illustrates the Graduate Attribute tracking roles and responsibilities at these various levels. The Faculty office sets and manages the Graduate Attributes, which are established by the CEAB for all engineering programs. However, the management system also allows the Faculty to set additional attributes to include those arising in other external evaluations (such as the CIPS accreditation associated with the Faculty's Computer Science Program) and to push these to the programs in question. It also sets a soft constraint on the number of Learning Outcomes that can be assigned to a single GA, although these can be overridden at the Program level. Finally, it maintains the registration data for the tracked courses associated with each accredited program and manages the instructor licenses for the Vena Solutions software.

Program-level responsibilities, which are managed by the program directors of the respective departments, include mapping the curriculum according to the 12 Graduate Attributes and the CEAB's three levels of instruction: "introduced", "developed" and "applied". The program directors also establish the number of bins used to

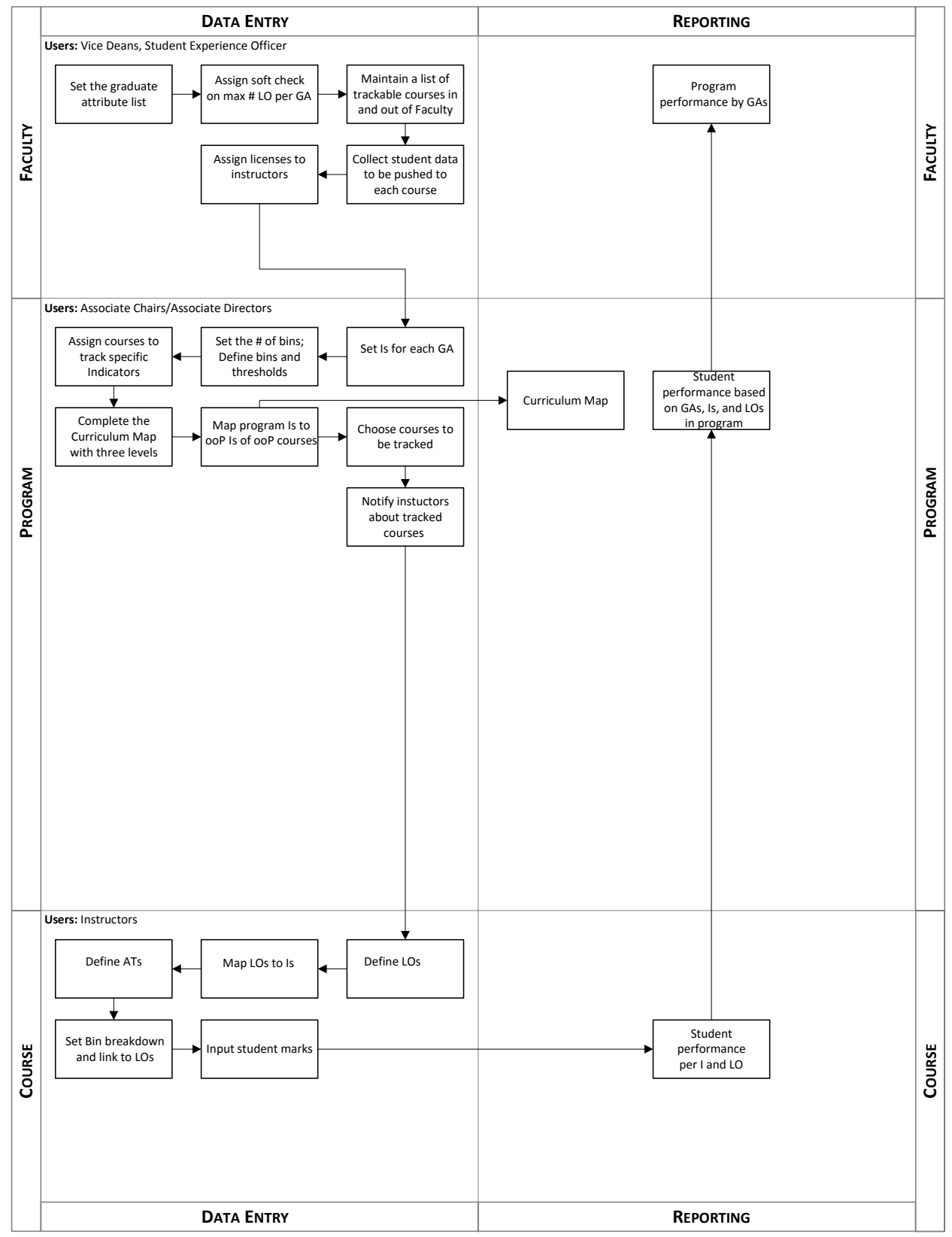

Fig. 1. Process flow for the three-level GA/Cl structure. 
categorize student performance gleaned from the tracked measurements and set the thresholds associated with each bin. A typical scenario involves four bins and grade levels: "exceeds" (A-and above); "meets" $(\mathrm{C}+$ to $\mathrm{B}+)$, "marginal" (D+ to C) and "fails" (D and below). While the number of bins form a hard constraint for all courses in the program, the associated levels are recommendations only instructors are able to modify these levels to better align with the expectations and degree of difficulty associated with a particular measurement. Finally, each semester the directors provide to the Faculty the list of instructors assigned to tracked courses for licensing purposes.

At the Course level, each instructor is tasked with defining the Learning Outcomes for their course and to map these to the Program-level Indicators. The simplest such mapping is one-to-one (a single LO for each I), but more complex mappings are permitted, where a given LO can be assigned to more than one I. Once the relationship between the LOs and Is has been established, the instructor must then determine the Assessment Tools to be used and associate these with the LOs of the course. As with the other mappings, the instructor is free to assign more than one AT to a given LO, with the caveat that the total contribution of multiple ATs to a single LO must sum to $100 \%$. This is accomplished by weighting the various AT inputs accordingly. Finally, the instructor must record the performance of all students registered to the course using the ATs.

With this administrative structure in mind, we will now turn to the specific design features of Vena Solutions' cloud-based database system for tracking Graduate Attributes.

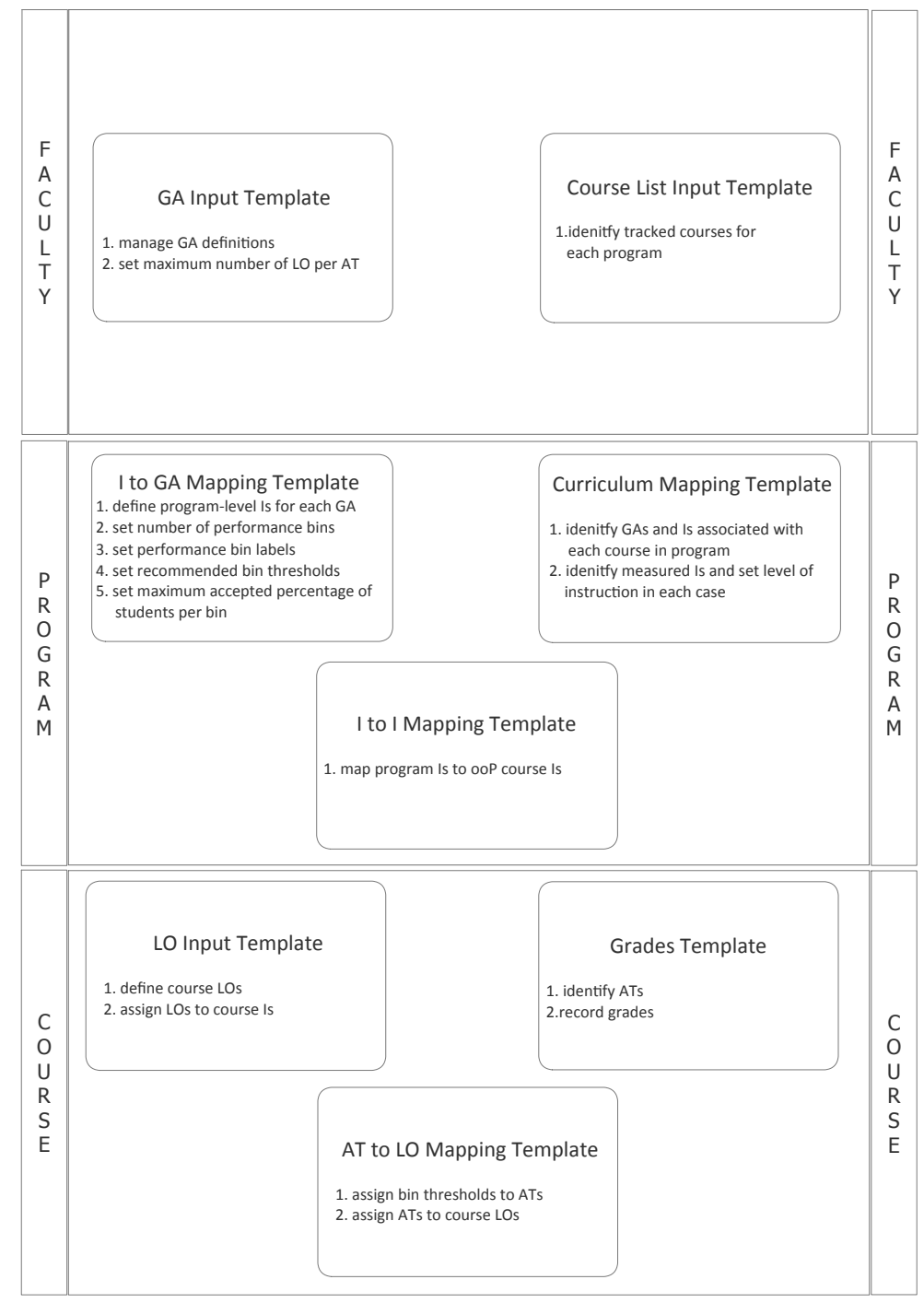

Fig. 2. Overview of the Vena Solutions-based template structure. 


\section{THE VENA GA MANAGEMENT SYSTEM: INPUT TEMPLATES AND REPORTS}

As Fig 1. illustrated, key tracking information is defined and subsequently transferred from each administrative level to its sublevel. This process of pushing information through the structure is accomplished by way of the Vena Solutions database system via a set of user interfaces, termed here templates, that are based on Microsoft Excel. Data entered into a given template is uploaded to the cloud and subsequently available to populate other templates. Figure 2 (previous page) highlights each administrative group's set of templates and their functions.

The Faculty administration manages two templates (Fig. 3): the first defines the various Graduate Attributes and sets the maximum number of Learning Outcomes that can be assigned to a single Assessment Tool, while the second identifies those courses in each program that are to be tracked (as established by the program itself).

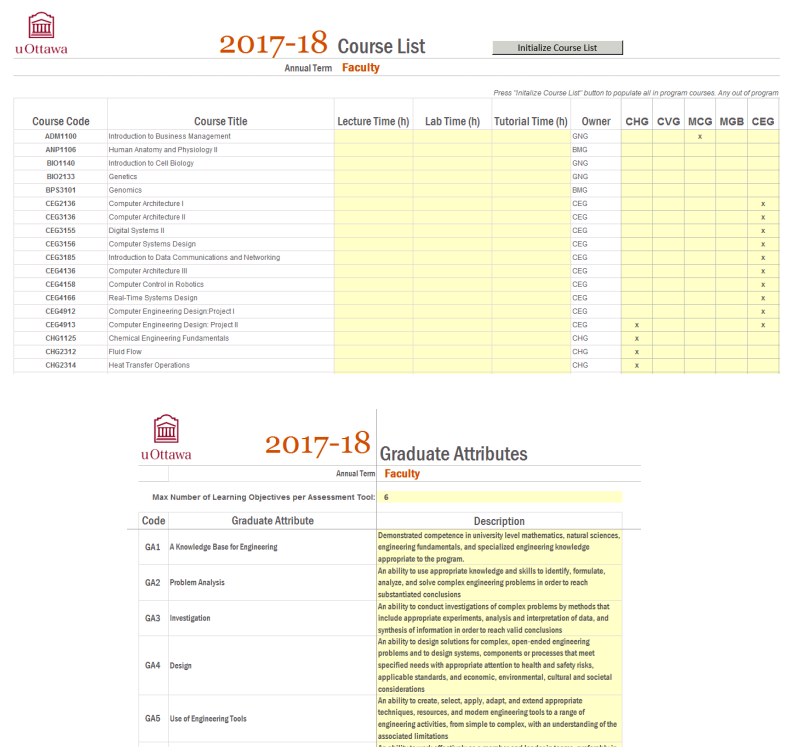

Fig. 3. Faculty Course List Input Template (top) and GA Input Template (bottom).

The program directors, meanwhile, work with three templates. The first (Fig. 4) establishes the Program-level Indicators associated with a given Graduate Attribute and also sets the number of assessment bins and their thresholds. In the second template (Fig. 5), the program directors enter their program's curriculum map, assigning to each course the GAs and Is associated with it, and identify which of these are to be measured. Finally, they must address out-of-Program (ooP) courses that have GAs and Is assigned to them by the hosting program and that do not necessarily align with those indicated by the client program's curriculum map. This is facilitated by the Indicator-to-Indicator template shown in Fig. 6.

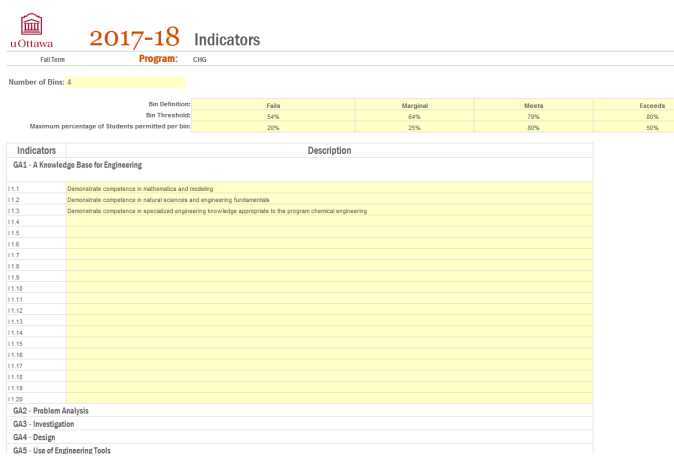

Fig. 4. Program-level Indicator Template.

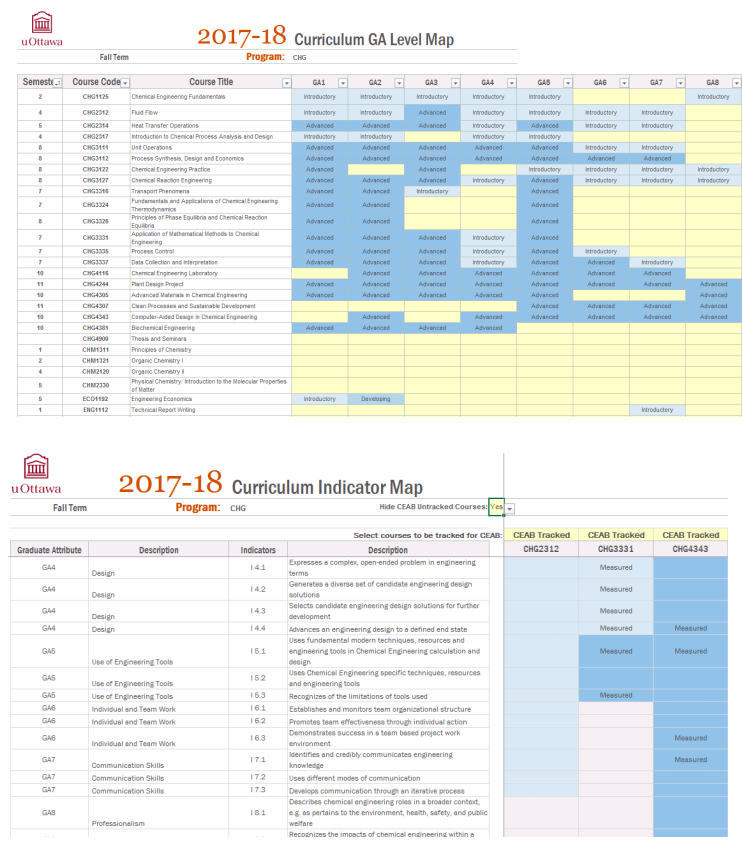

Fig. 5. Program-level Curriculum Map (top) and Course-Indicator Map (bottom).

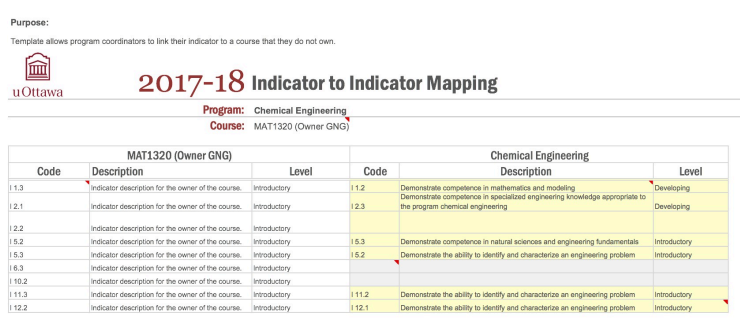

Fig. 6. Indicator-to-Indicator Template.

The final set of templates support GA tracking at the Course level (Fig. 7, next page). The first requires the instructor to define the course's Learning Outcomes and to associate these with the course's Indicators. As mentioned previously, the instructor is free to assign more than one 
LO to a given I, though this is not required. Next, the instructor must determine the Assessment Tools to be used to evaluate the LOs (and hence Is) assigned to the course. This is done in the Grades Input Template, which also serves to record student performance with respect to each AT. The instructor also has the option to include assessments that are not part of the data used to assess GA performance in the course - these additional assessments are said to be "untracked". In the final template, the instructor sets the bin thresholds pertaining to each AT and also associates one or more AT with each LO. When more than one assessment is assigned to a given LO, these must be weighted such that the total contribution of all ATs to a given LO sum to $100 \%$.

As mentioned earlier, the Excel interface is linked to a database. One significant outcome of this is that a
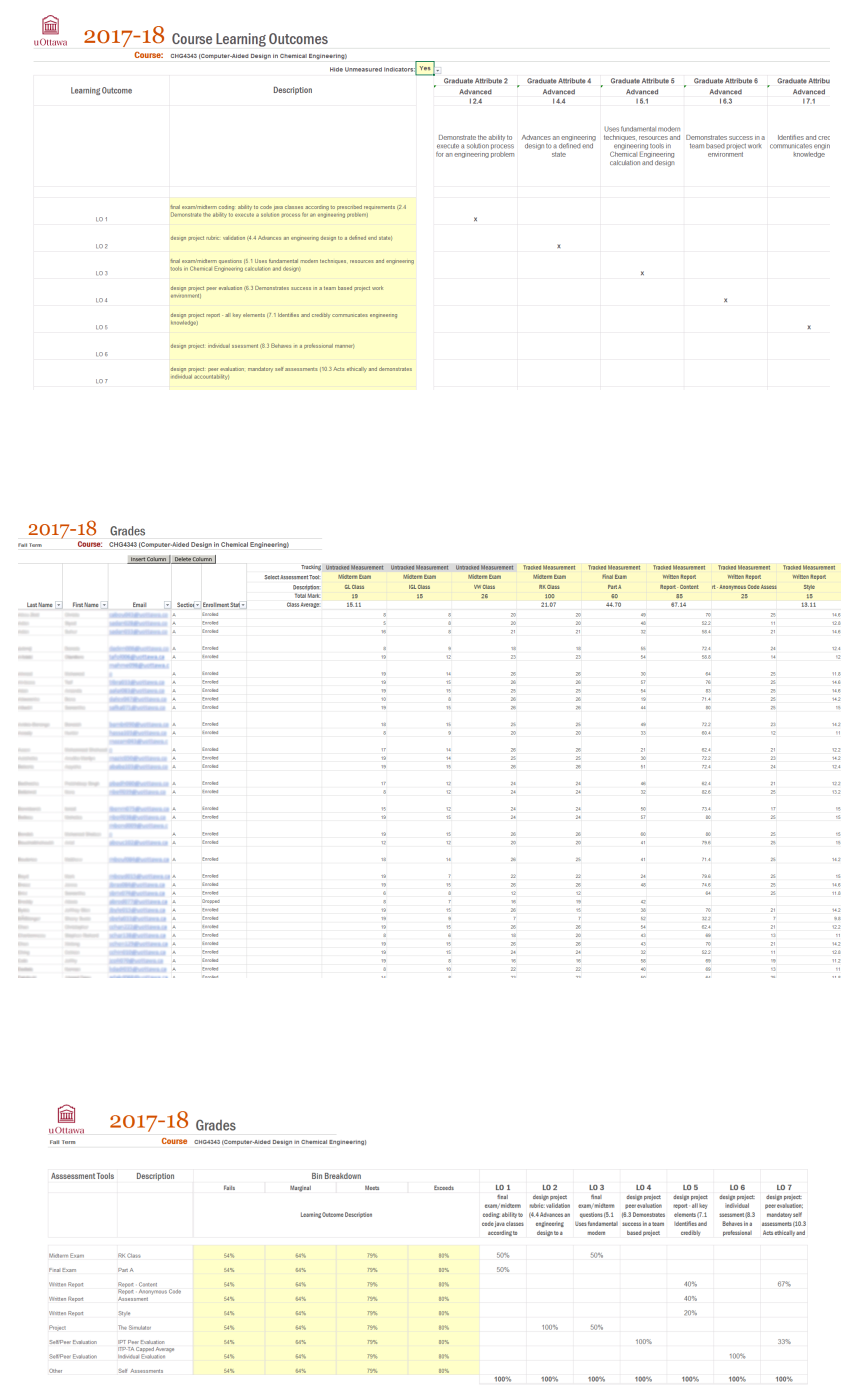

Fig. 7. The LO-to-I Mapping Template (top), the Grades Input Template (middle) and the AT-to-LO Mapping Template. spreadsheet cell is able to link to more than the data typical of an Excel workbook. In particular, one is able to attach to the cell digital files that will then be uploaded to the cloud database, along with all of the other spreadsheet data. This provides a very convenient method for storing information pertinent to standard accreditation visits, such as course outlines and samples of student work.

Whereas the flow of information for populating the templates begins at the Faculty level and moves downward, information flow for generating reports begins at the course level and moves upward. Overviews of the course-level data are provided through the Student Summary Report, Course Learning Outcomes Summary Report and the Course Indicator Summary Report (Fig. 8 below), which collectively provide tabulated and graphical data summarizing the students' weighted performance in a given course's assigned Graduate Attributes, Indicators and Learning Outcomes.

In addition to all of the associated course-level reports, program directors have access to two further reports: a
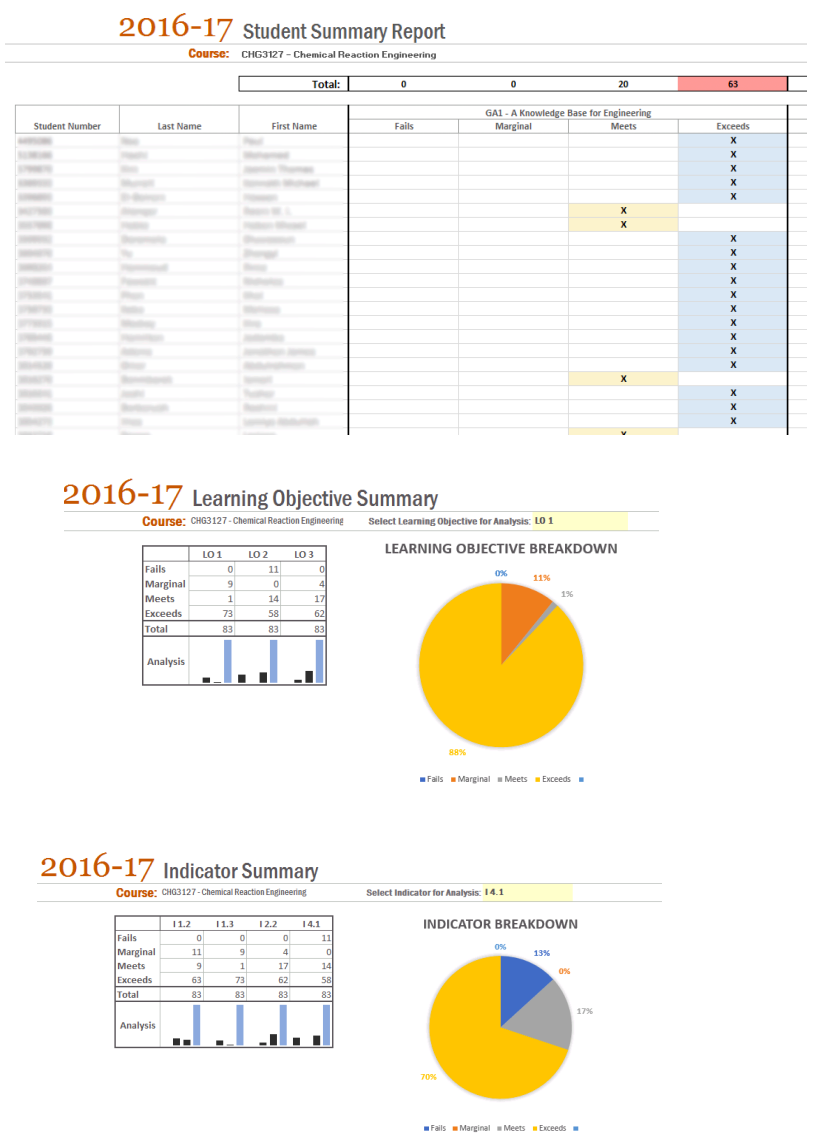

Fig. 8. The Student Summary Report (top), the Course Learning Outcomes Summary Report (middle) and the Course Indicator Summary Report (bottom). 
Program Summary Report that provides tabulated data pertaining to the Graduate Attributes and Indicators for each course in the program, and a Program Analysis Report that allows a director to select a particular GA and to view its accompanying data graphically (see Fig. 9).

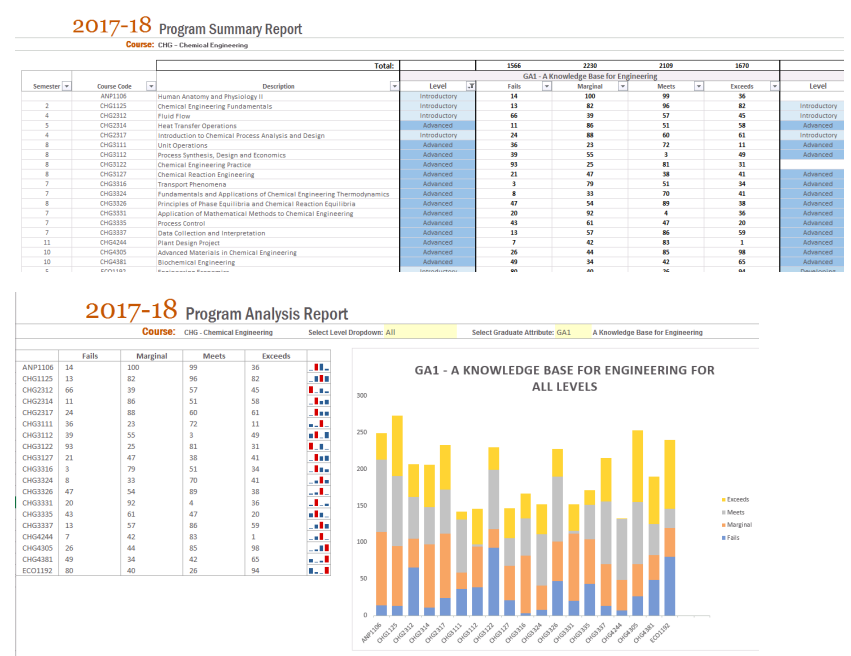

Fig. 9. The Program Summary Report (top) and Program Analysis Report (bottom).

Finally, while no Faculty-specific reports have been designed, Faculty administrators overseeing the Graduate Attribute tracking process have access to all of the courseand Program-level reports described above.

\section{CONCLUSIONS}

For many engineering undergraduate administrations, data collection, compilation and analysis for the purpose of the Continual Improvement Process (CIP) have posed considerable challenges. Some of these, however, can be mitigated through tools that can be aligned with, and integrated into, the administrative structure of a Faculty's CIP. For some programs at least, the tool of choice has been Microsoft Excel, which offers the advantages of being both ubiquitous and well accepted amongst the various academic stakeholders in the CIP. The disadvantage of this approach, however, is that Excel is not a data management system per se and therefore not well suited to handling large data pools from distributed sources.
Vena Solutions' Excel-based service provides one means for allowing Faculties to leverage the advantages of Excel whilst enjoying the benefits of a comprehensive data management system. The Faculty of Engineering at the University of Ottawa continues to develop and test this service to accommodate its own Graduate Attribute tracking and Continual Improvement Process.

\section{Acknowledgements}

The author gratefully acknowledges Dr Andrew Sowinski for generating Figure 1. and invites readers' questions regarding the $\mathrm{GA} / \mathrm{CI}$ implementation at the University of Ottawa.

\section{References}

[1] M. Isaacson, "Graduate attributes and accreditation," Canadian Civil Engineer, Spring Issue 33.1: 19-21, 2016

[2] J. Kaupp, B. Frank, R. Brennan, S. McCahan, L. Narayanan, P. Ostafichuck, N. Sepehri, and K. C. Watts, "A comparison of institutional approaches to CEAB graduate attribute requirements," Proceedings of Canadian Engineering Education Association Conference, Winnipeg, MB, DOI: http://dx.doi.org /10.24908/pceea. v0i0.4642, June 2012

[3] A. George, L. Peyton and V. Groza, "Graduate attribute information analysis system (GAIA) -from assessment analytics to continuous program improvement," 14th International Conference on Engineering of Modern Electric Systems, Oradea, Romania, DOI: 10.1109/EMES.2017.7980398, June 2017

[4] Said M Easa, "Framework and guidelines for graduate attribute assessment in engineering education," Can. J. Civ. Eng. 40: 547-556, 2013

[5] Jake Kaupp and Brian Frank, "Evaluation of software tools supporting outcomes-based continuous program improvement processes: part 3," Proceedings of Canadian Engineering Education Association Conference, Hamilton, ON, DOI: 10.24908/pceea. v0i0.5856, June 2015 